\title{
Value change and the recall of earlier values
}

\author{
GEORGE R. GOETHALS and MARNIE FROST \\ Williams College, Williamstown, Massachusetts 01267
}

\begin{abstract}
Several laboratory experiments have shown that when people change their opinions they tend to distort their initial positions so as to make them consistent with their final positions. The present study attempted to demonstrate this phenomenon for naturally occurring attitude changes. Thirty subjects who had completed the Allport-Vernon-Lindzey Study of Values scale 7 months earlier completed it a second time and attempted to duplicate their prior responses. Fifteen stated their current opinions first and then tried to duplicate their original responses, while the other 15 subjects proceeded in the reverse order. Subjects were unable to recall earlier values accurately and thus perceived less change than had actually occurred. There were high correlations between final and recall value scores regardless of the order of measurement.
\end{abstract}

Several recent studies have shown that when people change their attitudes, they tend to perceive their original attitudes as being similar to their final ones. For example, in a study by Bem and McConnell (1970), subjects who wrote counterattitudinal essays and changed their attitudes recalled their initial positions as being almost identical to their new attitudes. Similarly, Goethals and Reckman (1973) found that after an attitude change-producing discussion, subjects' recall of their original positions was distorted so as to make them consistent with their new attitudes.

The purpose of the present study was to see whether this recall phenomenon takes place with attitude change that occurs in the natural course of events over time. It was specifically concerned with value changes, and perception of value changes, on the Allport-Vernon-Lindzey (1960) Study of Values scale. This scale measures subjects' relative interest in six areas of value: theoretical, economic, aesthetic, social, political, and religious. Copies of the scale had been sent to 482 college freshmen just prior to the start of the fall term. Later, a subgroup was chosen randomly from the $80 \%$ who originally responded, so as to investigate how much value change, or consistency, was perceived in relation to the changes that had actually occurred, and, more specifically, whether new values would predict recall of former values better than original values, as has been found in earlier studies.

Another purpose of the present study was to investigate whether varying the measurement sequence would make a difference in subjects' recall of initial attitudes. In a study by Shaffer (1975), half of the subjects, who had written counterattitudinal essays, were asked to state their current attitude first, and then

The research reported in this paper was supported by NIMH Grant MH-23527. Reprint requests should be sent to George R. Goethals, Department of Psychology, Williams College, Williamstown, Massachussetts 01267. try to recall their initial position (final-recall sequence), while the other subjects gave the same information in reverse order (recall-final sequence). Shaffer found that recall scores were significantly more highly correlated with new attitudes in the recall-final sequence than in the final-recall sequence. Since Shaffer's results are not entirely consistent with those of earlier studies and raise important issues, the final-recall vs. recall-final variation was included in the present study in the hope of making some assessment of the impact of this factor.

\section{METHOD}

\section{Subjects}

Subjects were 30 men and women first-year undergraduate students at Williams College, chosen randomly from among those who had completed the Allport-Vernon-Lindzey scale during the summer prior to their entry into college. Subjects were scheduled in groups of three to five and groups were assigned randomly to one of the two (final-recall and recall-final) conditions. Subjects were paid $\$ 2$. There were 15 subjects in each condition.

\section{Procedure}

The experiment was conducted in the spring of the academic year, 7 months after the value scale had been initially completed. In the recall-final condition, the experimenter told the subjects that she was interested in seeing how accurately they could recall the way they had completed the Scale of Values 7 months earlier. They were asked to duplicate their original responses as closely as possible. After the "recall" procedure had been completed, the experimenter explained that she also wanted to measure student values at the present time and asked the subjects to fill out the scale once again, indicating their present feelings. The order of instruction was reversed for the subjects in the final-recall condition. When the scales had been completed, subjects were debriefed, given their original value scores, and thanked for their participation.

\section{RESULTS}

Value change was assessed by examining each subject's degree of change on each value regardless of direction. The mean absolute change scores tended to 
be slightly higher in the recall-final condition than in the final-recall condition. For the six values, the mean changes ranged from 4.70 to 6.03 in the recall-final condition and 3.20 to 5.07 in the final-recall condition. Summing across the six values, the mean total absolute change was 31.40 in the recall-final condition and 24.13 in the final-recall condition. The difference between these means does not approach significance $(\mathrm{t}=1.27)$.

Perceived value change was assessed by examining the difference between each subject's final and recall scores on each value regardless of direction. Summing across the six values, perceived change was nearly identical in the recall-final $(M=18.67)$ and final-recall $(M=19.33)$ conditions. Collapsing across conditions, the mean perceived changes ranged from 2.67 to 3.57 for the six values, as compared to 4.00 to 5.28 for actual changes. The difference between total perceived change $(M=19.00)$ and total actual change $(M=27.77)$ for all subjects was significant $(\mathrm{t}=2.85, \mathrm{p}<.01)$.

The correlations between final scores and recall scores on each of the six values were very high and roughly equal in both conditions. In the recall-final condition, correlations ranged from .84 to .97 , with an average of .91 , while in the final-recall condition, the correlations ranged from .81 to .96 , with an average of .88 . For all subjects the correlations ranged from .83 to .94 , with an average of .89 . Original and recall scores were also highly correlated (for all subjects, the correlations ranged from .68 to .82 with an average of .76). However, final-recall correlations were higher than original-recall correlations for every value. The difference between the correlations was significant for four values: the political $(p<.01)$, the economic $(p<.02)$, the social, $(p<.02)$, and the theoretical $(\mathrm{p}<.05)$. The difference in correlations was not significant for the religious $(t=1.56, p<.20)$ and aesthetic $(\mathrm{t}=.26, \mathrm{n} . \mathrm{s}$. $)$ values.

\section{DISCUSSION}

A variety of experimental studies show that following attitude change, people perceive their original position as being close to their final one. The results of the present study, investigating the consequences of naturally occurring attitude change, are consistent with those of studies investigating the consequences of laboratory-produced attitude change. Furthermore, unlike previous studies that have focused on one attitude only, this study was concerned with a variety of attitudes. That is, the same attitude recall phenomenon has now been demonstrated under very different circumstances.

In relation to the order of measurement issue, the results of the present study do not support Shaffer's (1975) findings. Shaffer argues that the high correlation between recall and final attitudes found by Bem and McConnell (1970) is due to their recall-final order of measurement. He contends that subjects in a final-recall variation may be less reluctant to admit a discrepancy between old and new attitudes than their counterparts in a recall-final variation. However, Shaffer's results are not entirely consistent with those of Bem and McConnell (1970), in that they show a large difference between attitude change and recall error. Bem and McConnell found attitude change to be very close to recall error. Shaffer's findings also differ from those of Goethals and Reckman (1973) who used the final-recall order but found a correlation between recall and final attitudes very similar to the correlation found by Bem and McConnell. The present study seems consistent with the Bem and McConnell and Goethals and Reckman studies in finding high correlations between recall and final attitudes that are nearly identical in both measurement variations.

In conclusion, the results of the present study indicate that people often are not totally aware of the extent to which they change their attitudes and that their recall of their attitudes at an earlier time is more highly correlated with their present attitudes than their earlier ones.

\section{REFERENCES}

Allport, G. W., Vernon, P. E., \& Lindzey, G. L. Study of values. Boston: Houghton Mifflin, 1960.

BEM, D. J., \& MCConnell, H. K. Testing the selfperception explanation of dissonance phenomena: On the salience of premanipulation attitudes. Journal of Personality and Social Psychology, 1970, 14, 23-31.

Goethals, G. R., \& Reckman, R. F. The perception of consistency in attitudes. Journal of Experimental Social Psychology, 1973, 9, 491-501.

Shaffer, D. R. Another look at the phenomenological equivalence of pre- and postmanipulation attitudes in the forced-compliance experiment. Personality and Social Psychology Bulletin, 1975, 1, 497-500.

(Received for publication October 24, 1977.) 